
\title{
25 Research Square \\ p21 inhibitor UC2288 ameliorates MPTP induced Parkinson's disease progression through inhibition of oxidative stress and neuroinflammation
}

Jun Hyung Im

Chungbuk National University College of Pharmacy

In Jun Yeo

Chungbuk National University College of Pharmacy

Seong Hee Jeon

Chungbuk National University College of Pharmacy

Dong Hun Lee

Chungbuk National University College of Pharmacy

Hyeon Joo Ham

Chungbuk National University College of Pharmacy

Jaesuk Yun

Chungbuk National University College of Pharmacy

Sang-Bae Han

Chungbuk National University College of Pharmacy

Jin Tae Hong ( $\boldsymbol{\sigma}$ jinthong@chungbuk.ac.kr)

Chungbuk National University https://orcid.org/0000-0002-6534-9575

\section{Research}

Keywords: Parkinson's disease, p21 inhibitor, UC2288, MAPK, Parkin

Posted Date: April 17th, 2020

DOI: https://doi.org/10.21203/rs.3.rs-19130/v1

License: (1) (1) This work is licensed under a Creative Commons Attribution 4.0 International License.

Read Full License 


\section{Abstract}

\section{Background}

Parkinson's disease (PD) is a neurodegenerative disease characterized by the early prominent death of dopaminergic neurons and a decrease of dopamine levels. Dopamine depletion leads to several motor dysfunctions, including resting tremor, muscular rigidity, bradykinesia and postural instability. Our previous study determined that knockout of parkin, a gene of PD degrade $\mathrm{p} 21$, suppresses neurogenesis which is critical for a neurodegenerative disease.

\section{Methods}

Thus, we investigated the effect of UC2288, an inhibitor of p21, for its therapeutic effect on PD. We found that UC2288 attenuated 1-methyl-4-phenyl-1,2,3,6-tetrahydropyridine (MPTP)-induced behavioral impairment in Rota-rod and Pole test as well as dopamine depletion.

\section{Results}

Moreover, UC2288 recovered the number of TH positive cells, but decreased the number of GFAP and Iba1 positive cells accompanied the decrease of BAX and cleaved caspase 3 as well as iNOS and COX-2 expression. In cultured neurons, UC2288 recovered MPP+-induced neuronal cell death in a concentration dependent manner. We also found that UC2288 decreased the p21 reactive cell number, oxidative neuronal damages, cytokines product in vivo and cultured neurons. In a mechanism study, we found that UC2288 significantly decreased the activation of ERK and p38 kinase pathway in the mitogen-activated protein kinase (MAPK) pathway. In addition, 1-10 $\mu$ M concentration of ERK kinase inhibitor U0126 recovered MPP+-induced neuronal cell death. However, ERK kinase inhibitor U0126 further decreased cell viability with the increase of $\mathrm{H}_{2} \mathrm{O}_{2}$.

\section{Conclusion}

These results indicated that the administration of UC2288 exerted neuroprotective effects on the death of dopaminergic neurons through the suppression of oxidative stress and neuroinflammation via ERK pathway inhibition.

\section{Background}

Parkinson's disease (PD) is a common chronic neurodegenerative disease characterized by muscle tremor, as well as decreased mobility and coordination capacity ${ }^{12}$. The pathogenesis of PD is associated to the degeneration of dopaminergic neurons ${ }^{3}$. This degeneration of dopaminergic neurons reduces the dopamine content in cerebral cortex ${ }^{3}$. Although L-dopa therapy has been the mainstay of PD therapy since $1969^{4}$, limitations of its efficacy and side effects have necessitated the development of new target oriented drugs ${ }^{5}$. Moreover, as dopaminergic drugs cannot easily penetrate the Brain-blood-barrier, they 
need to be systemically administered at a high dose. Therefore, other treatment strategies such as aromatic amino acid decarboxylase (AADC), glutamic acid decarboxylase (GAD) and glial cell line-derived neurotrophic factor (GDNF) gene therapy have all been suggested ${ }^{6-8}$.

Reactive Oxygen Species (ROS) may result in significant damage to cell structures. In PD, ROS is a major cause of neuronal death. In animal models of PD-like symptoms, ROS causes the activation of microglial cells which subsequently attack neighboring dopaminergic neurons ${ }^{9}$. Vitamin E scavengers several ROS, thus inhibiting lipid peroxidation ameliorates the severity of PD ${ }^{10}$. A combination of ascorbate and atocopherol has also used for patients with early PD ${ }^{9}$. The neuroprotective effects of $\mathrm{CoQ}_{10}$ have been shown in MPTP-induced mice and in a monkey model ${ }^{1112,}$.

Several studies have demonstrated the involvement of the mitogen activated protein kinase (MAPK) pathway in the development of PD. The p38 MAPK activation was increased in a 6-hydroxydopamine (6OHDA) induced mouse PD model, and it was also implicated in the mechanism of neuronal cell death ${ }^{13-}$ 15. a-Synuclein, a marker of PD, activated P38, ERK, and JNK pathways to produce IL-1 $\beta$ and TNF-a, and thus promoted neuroinflammation in human microglial cells ${ }^{16}$. Moreover, rotenone induced the activation of JNK and p38 MAPK caused apoptosis in dopaminergic SH-SY5Y cell death ${ }^{17}$. However, the inhibition of JNK attenuated neuronal apoptosis and increased dopamine levels in both in vitro and in vivo models of PD ${ }^{18}$. It has also been reported that mice deficient in JNK3 were more resistant to dopaminergic neuron survival by MPTP than their corresponding wild-type ${ }^{19}$. Treatment of dopaminergic cells with 6-OHDA activated ERK1/2 pathway, as well as pharmacological inhibition of the ERK pathway enhanced neuronal survival ${ }^{20}$. Many studies have also demonstrated that ROS can induce the activation of the MAPK pathways in neuronal cell death ${ }^{152122^{\prime \prime}}$.

Parkin, a ubiquitin E3 ligase, ubiquitinates proteins in order to regulate a variety of cellular processes, with its mutation begin the second most commonly known cause of PD ${ }^{23}$. Parkin knockout mice display normal performance on behavioral tests, but they experience disrupted memory and leak dopamine from the nerve ${ }^{24}$. Overexpression of parkin protected acute a-synuclein induced dopaminergic neurons in primary culture ${ }^{25}$ and in a rat brain ${ }^{26}$. In PD, the expression of $p 21^{\text {ras }}$ was increased in MPTP-induced mice brains ${ }^{27}$. Moreover, increased p21 degradation was formed in lymphocytes as a result of PD ${ }^{2829}$. It has also been reported that simvastatin inhibited p21 activation and prevented the loss of dopaminergic neurons in a mouse PD model ${ }^{27}$. Our previous study found that parkin knockout in a mouse inhibits neurodevelopment via the degradation of $\mathrm{p} 21^{1}$. Further RNA seq results revealed that $\mathrm{p} 21$ is closely related to both with SNAP25 and BDNF, as well as parkin in the brain of PD patient ${ }^{1}$. A recent study also indicated that the mutation of reduced solubility and E3 ligase activity resulted in progressive neuronal degeneration through the accumulation of toxic proteins ${ }^{30}$. It was also found that parkin expression protects $6-\mathrm{OHDA}$ induced neuronal damages ${ }^{31}$. Therefore, it is possible that knockout parkin could not degrade p21, and its accumulation may inhibits neurogenesis causing the progression of 
neurodegenerative disease such as PD. Thus, in the present study, we investigated whether a p21 inhibitor could be effective for the treatment of PD and its action mechanisms.

\section{Methods}

\section{Modeling method}

MPTP was used to establish the PD mice (C57BL6) model. Each mouse in MPTP group received intraperitoneal injection of MPTP $20 \mathrm{mg} / \mathrm{kg}$ for 4 times in 7 days, while the same amount of normal saline was injected to each mouse in CON group. UC2288 group each mouse was injected with $10 \mathrm{mg} / \mathrm{kg}$ UC2288 and MPTP + UC2288 group treated MPTP $(20 \mathrm{mg} / \mathrm{kg})$ with UC2288 $(10 \mathrm{mg} / \mathrm{kg})$ for 4 times in 7 days by intraperitoneal injection under the guideline of National Institute of Toxicological Research Korea and Drug Administration for the human care and use of laboratory animals and approved by IACUC of Chungbuk National University CBNUR-1117-18. 1-2 $\mathrm{h}$ later after the last injection, the behavioral tests and biochemical experiments were conducted in succession.

\section{Behavior Tests}

Behavior changes were tested by Rota rod, Pole and gait tests as described elsewhere ${ }^{32}$. Motor performance and coordination were examined using the Rota rod treadmill (MED Associates Inc., St. Albans, VT.), consisting of a 3.6-cm diameter cylindrical treadmill connected to a computer controlled stepper motor as described previously ${ }^{33}$. The pole test trials were performed using the rough-surfaced wooden pole three times per animal and average values from three examinations were used for each animal. A gait test trial was performed on a bright runway $(4.5 \mathrm{~cm}$ wide) and a dark goal box $(20 \times 17 \times$ $10 \mathrm{~cm}$ ) and stride length was measured as the distance between successive paw prints. Data was presented as the average of five strides for each animal.

\section{Cresyl Violet Staining}

The brains were post fixed in $4 \%$ paraformaldehyde for $24 \mathrm{~h}$ at $4{ }^{\circ} \mathrm{C}$, and then transferred to $30 \%$ sucrose solutions. $25-\mu \mathrm{m}$ brain sections were thoroughly washed with phosphate-buffered saline (PBS), and then remove the excess fixative agent and then transferred to gelatin-coated slide glasses and stained with $0.1 \%$ cresyl violet $(2-5 \mathrm{~min}$ ) for the purpose of identifying cortical layers and cytoarchitectural features of the isocortical region. After this, the sections were washed in distilled water then dehydrated through ascending grades of ethanol, 50,70,90, and 100\% ethanol for $2 \mathrm{~min}$ in each grade followed by $10 \mathrm{~min}$ immersion in a 1:1 mixture of absolute alcohol and xylene. They were cleared in xylene for 5-10 min and mounted in mounting medium (Cytoseal ${ }^{\text {TM }} \mathrm{XYL}$; Thermo Scientific, Pittsburgh, CA).

\section{Oxidative Stress Assay}


The MDA concentration in brain tissue and neuronal cells were determined based on thiobarbituric acid (TBA) reactivity (Cell Biolabs, Inc. San Diego, CA) by the manufacture's guidance. Briefly, trichloroacetic acid with $\mathrm{HaCaT}$ keratinocytes mixture were centrifuged, and then supernatant was related with TBA. The reactingr color was measured at $532 \mathrm{~nm}$ with a spectrophotometer. $\mathrm{H}_{2} \mathrm{O}_{2}$ binds to molybdenic acid complex was assessed using a commercially available kit (DCFH-DA, Sigma Aldrich) specifically as a $\mathrm{H}_{2} \mathrm{O}_{2}$ content at $405 \mathrm{~nm}$, and the $\mathrm{H}_{2} \mathrm{O}_{2}$ content was then calculated. GSH-Px activity was determined by the velocity method using a GSH-Px kit (DCFH-DA, Sigma Aldrich). The change in absorbance during the conversion of GSH to GSSG was recorded spectrophotometrically at $412 \mathrm{~nm}$ as GSH-Px activity. SOD production of ARBEC was assessed with a superoxide anion assay kit (Catalog Number CS1000, Sigma, USA). The cells were grown in none serum medium, and they were treated with $100 \mu \mathrm{M} \mathrm{MPP}+$ for $24 \mathrm{~h}$ or with 10, 20, $50 \mathrm{nM}$ UC2288. Cell suspensions (90 $\mu$ l each) were added to the 96 -well plate containing $5 \mu \mathrm{l}$ of luminol solution (Catalog Number L5043) and $5 \mu$ l of enhancer solution (Catalog Number E4281), and the samples were mixed with a micropipette. After a 15 min incubation period, the luminescence intensity was measured with an Orion II Microplate Luminometer (Berthold, Germany).

\section{Western Blot Analysis}

The brain tissues were homogenized with lysis buffer (PROPREP; iNtRON, Sungnam, Korea; $\mathrm{n}=8$ mice per group) and centrifuged at $2,500 \times \mathrm{g}$ for $15 \mathrm{~min}$ at $4{ }^{\circ} \mathrm{C}$. Equal amounts of total protein $(40 \mu \mathrm{g})$ isolated from brain tissues were resolved on 8 or $10 \%$ sodium dodecyl sulfate polyacrylamide gels and then transferred to nitrocellulose membranes (Hybond ECL; Amersham Pharmacia Biotech, Piscataway, NJ). Membranes were incubated at roomtemperature for $2 \mathrm{~h}$ with the following specific antibodies: anti-parkin, anti-ubiquitin, anti-ERK, anti-p-ERK, anti-p-P21, anti-p-P38, anti-P38, anti-p-JNK, anti-JNK (Cell Signaling Mol Neurobiol Technology, Inc., Beverly, MA), anti-BAX, anti-cleaved caspase-3 (1:1,000; Santa Cruz Biotechnologies, Inc., Santa Cruz, CA) and anti- $\beta$-actin (1:2,500; Sigma, St Louis, MO). Blots were then incubated at room temperature for $2 \mathrm{~h}$ with, corresponding peroxidase-conjugated anti-mouse or antirabbit antibodies (1:2,000; Santa Cruz Biotechnology, Inc., Santa Cruz, CA). Immunoreactive proteins were detected using an enhanced chemiluminescence (ECL) Western blotting detection system. The relative density of the protein bands was scanned densitometrically using My Image (SLB, Seoul, Korea) and quantified by Lab Works 4.0 (UVP, Upland, CA).

\section{Immunohistochemistry And Immunofluorescence}

Immunohistochemistry and immunofluorescence analyze were done as describe elsewhere ${ }^{32}$. Using paraffin-embedded tissue sections after incubated with p-p21 anti-mouse IgG antibody (1:1000 dilution; Vector Laboratories, Burlingame, CA, USA) After subsequently washed and incubated with avidinconjugated peroxidase complex (ABC kit, 1:200 dilution; Vector Laboratories), the tissue section was stained with 3, 3'- diaminobenzidine tetrahydrochloride (DAB, 0.02\%) as the chromogen. And evaluated via light microscopy (Olympus, Tokyo, Japan). For immunofluorescence examination, sections were 
incubated with anti-mouse secondary antibody labeled with Alexa-Fluor 568 (1:400 dilution; Invitrogen). The final images were acquired using a confocal laser scanning microscope (TCS SP2, Leica Microsystems AG, Werzlar, Germany).

\section{Levels Of IL-6, IL-1 $\beta$ And TNF- $\alpha$ Of Protein}

According to the instruction of manufacture, the level of IL-6, IL-1 $\beta$ and TNF was measured by a sandwich enzyme-linked immunosorbent assay (ELISA) as described elsewhere ${ }^{34}$. The IL-6, IL-1 $\beta$ and TNF level in the blood were expressed as picogram of cytokines per milligram of protein.

\section{Cell Culture And Treatment}

Pregnant SD rats are delivered by DBL Company $48 \mathrm{~h}$ before sacrify in a calm room. Embryos were removed from pregnant (day 17) SD rats (DBL, South Korea) under intraperitoneal pentobarbitol (SigmaAldrich, UK) anesthesia. Cortices were dissected, and treated with papain (10 U/mL, Sigma-Aldrich, UK), then exposed for $5 \mathrm{~min}$ in Phosphate Buffer Saline (PBS) solution containing: DNAse I (Invitrogen, Thermo Fisher Scientific, Waltham, USA) and B27 (Gibco, Thermo Fisher Scientific, Waltham, USA), and D-glucose (33 mmol/L, Sigma-Aldrich, UK). Cells were then dissociated by trituration and filtered through a membrane (70 Im, BD Falcon). Cells were then purified with a BSA solution (8\%, Sigma-Aldrich, UK) diluted in Neurobasal A-25 (Invitrogen, Thermo Fisher Scientific, Waltham, USA). (0.1 mg/mL, SigmaAldrich, UK). For each experiment, cortices from 8 to 12 embryos per rat are mixed. Experiments were reproduced three to eight times. Cells were grown in poly-D-lysine coated dishes Neurobasal (Eurobio) supplemented with B27 medium (Invitrogen, Thermo Fisher Scientific, Waltham, USA), containing $2 \mathrm{mmol} / \mathrm{L}$ glutamine, $0.1 \%$ penicillin and streptomycin (Gibco, Thermo Fisher Scientific, Waltham, USA), $250 \mathrm{U} / \mathrm{mL}$ amphotericin (Invitrogen, Thermo Fisher Scientific, Waltham, USA), and $1 \mathrm{mmol} / \mathrm{L}$ lactic acid (Sigma-Aldrich, UK) at a density of $6 \times 10^{5}$ cells per $\mathrm{cm}^{2}$. The percentage of neuronal cells in our culture system is more than $90 \%$ judged with cell morphology and immunostaining measurement. Cells were incubated at $37^{\circ} \mathrm{C}$ and $95 \%$ humidity with $5 \% \mathrm{CO}^{2}$. When the cells reached $\sim 80 \%$ confluence, the cells were then treated either with freshly prepared MPP + in DMSO (100 nM final concentration).

\section{TUNEL Assay}

Cell Death Detection Kit (Roche Diagnostics GmbH, Mannheim, Germany) was used for TUNEL assay according to the manufacturer's instructions. briefly, after fixation of $25-\mathrm{mm}$ cryosections with $4 \%$ paraformaldehyde, $0.1 \% \mathrm{NaBH} 4$ and 0.1 Triton $\mathrm{X}-100$ was treated The slides were then incubated for at least $1 \mathrm{~h}$ with mixture reaction buffer containing deoxynucleotidyl transferase and FITC- dUDP (Roche, Reinach, Switzerland). For 40, 60-diamidino-2-phenylindole dihydrochloride (DAPI) staining, the slides were then incubated for $15 \mathrm{~min}$ at room temperature in the dark with a mounting medium for fluorescence containing DAPI (Vector Laboratories, Cambridgeshire, UK). The tissues were then examined 
through a fluorescence microscope (Leica Microsystems AG, Wetzlar, Germany), and the nuclei were visualized via DAPI staining.

\section{Statistical Analysis}

GraphPad Prism 4 software (GraphPad Software, La Jolla, CA) was used for statistical ananlysin. A oneway analysis of variance (ANOVA) was applied for assessment of difference among the graph. Once the significant was found, the differences were further analyzed by the Dunnett's test. Data are presented as mean $\pm S D$, a value of $P<0.05$ was considered to be statistically significant.

\section{Results}

\section{Effect of UC2288 on behavioral impairments by MPTP}

We examined the effect of UC2288 on behavior disorders by MPTP. The rota-rod test was conducted in order to test coordination capability. The MPTP treated group significantly decreased latency on the rotarod. However, the latency in the MPTP with UC2288 $(10 \mathrm{mg} / \mathrm{kg})$ co-treated mice $(44.7 \pm 49.5 \mathrm{~s})$ was significantly increased compared to that in the MPTP treated mice $(94.8 \pm 32.5 \mathrm{~s})$ (Fig. 1A). Next, we performed the pole test, which measures the time descending from the top of the pole to the floor. The time is considered to reflect bradykinesia. The control and UC2288 treated groups did not show any significant differences as far as behavior disorders. However, the time to descend was significantly decreased in the MPTP with UC2288 $(10 \mathrm{mg} / \mathrm{kg})$ treated mice $(22.8 \pm 6.49 \mathrm{~s})$ compared to that in the MPTP treated mice $(41.0 \pm 1.0 \mathrm{~s})(\mathrm{Fig} .1 \mathrm{~A})$. When the stride length test was performed, the results showed that the stride length of the hind limb was lengthened by more in the MPTP with UC2288 co-treated mice $(4.9 \pm 0.6 \mathrm{~cm})$ than in the MPTP treated mice $(4.5 \pm 0.3 \mathrm{~cm})($ Fig. $1 \mathrm{~A})$. However, there was no significant difference found in terms of behavior disorders between MPTP treated mice and MPTP with UC2288 cotreated mice.

\section{Effect Of UC2288 On MPTP-induced Apoptosis In Mice Brains}

Cresyl violet staining was performed in order to assess the cell death in the striatum. We counted the number of stained cells indicated by cresyl violet. The average number of stained cells in the UC2288 treated mice brains was $691.658 / \mathrm{cm}^{2}$, compared to that $\left(390.29 / \mathrm{cm}^{2}\right)$ in MPTP treated mice (Fig. 1B). This result indicated that UC2288 suppressed MPTP-induced neurological cell death. Western blot data for BAX and cleave-caspase3 (a pro-apoptotic protein) expression was also decreased in the MPTP and UC2288 treated mice brain compared to the expression in MPTP treated mice brains (Fig. 1C). 


\section{Effect Of UC2288 On ROS Generation And Lipid Peroxidation}

It was well known that MPTP induces an oxidized lipid by forming a high ROS level, which is a critical factor for neuronal cell death. Therefore, we examined ROS generation and lipid oxidation in the MPTP treated mice brains. The ROS level was elevated by MPTP, however, the elevated ROS was reduced by the treatment of UC2288 (10 mg/kg) (Fig. 2A). There was no significant difference in the ROS levels between the control and UC2288 (10 mg/kg) treated mice groups. We also determined lipid peroxidation through measuring the MDA level. The MDA levels were also significantly higher in the MPTP treated group, but these levels were also reduced by UC2288 treatment. There was no significant difference in MDA level between the control and UC2288 $(10 \mathrm{mg} / \mathrm{kg})$ treated mice groups. Moreover, the GSH/GSSG ratio was also increased by UC2288 treatment compared to MPTP treated mice (Fig. 2A).

\section{Effect Of UC2288 On Cytokine Level}

TNF-a, IL-6, and IL-1 $\beta$ all play important roles in neurodegenerative diseases, and these cytokines could be released by the oxidative stress of neuronal cells. We thus examined the cytokine levels. MPTP treatment raised TNF- $\alpha$, IL- 6 and IL- $1 \beta$ levels in MPTP treated mice brain. However, TNF- $\alpha$, and IL- 6 release were both significantly decreased by UC2288 treatment in MPTP treated mice brains, but IL-1 $\beta$ was not (Fig. 2B). There was no significant difference in cytokine level between control and UC2288 $(10 \mathrm{mg} / \mathrm{kg})$ treated mice brains.

\section{Effect Of UC2288 On Dopaminergic Neurodegeneration}

Abundant TH-positive fibers in the striatum and substantia nigra were found in the control and UC2288 treated groups, whereas the number of TH-positive neurons was significantly lowered in the striatum and substantia nigra of the MPTP treated mice brain. However, UC2288 treatment recovered the number of TH-positive neurons in MPTP treated mice. (Fig. 3A). In addition, the GFAP and Iba-1 reactivity was also reduced following treatment of UC2288 in MPTP treated mice (68.79 vs 53.43 cells $/ \mathrm{mm}^{2}$ ) (Fig. 3A). Treatment of UC2288 recovered dopamine level in the MPTP treated brain, which was associated with the recovery of TH positive cells (Fig. 3B).

\section{UC2288 prevented activation of MAPK pathway in the MPTP treated mice brain}

We speculated that MPTP-induced ROS generation might related to the activation of the MAPK pathway. Increased activation of the MAPK pathway in MPTP treated mice was found (Fig. 4A). However, UC2288, a p21 inhibitor suppressed the phosphorylation of p38 and ERK in the MPTP treated mice brains

(Fig. 4A). In addition, the MPTP-elevated expressions of iNOS and COX-2 were also decreased by UC2288 (Fig. 4B). 


\section{UC2288 Reduced ROS And Suppressed Cell Death In Vitro}

Treatment of MPTP causes the degeneration of dopaminergic neurons. Exposure for $24 \mathrm{~h}$ to MPTP up to $100 \mu \mathrm{M}$ causes cell death in cultured neurons. MTT assay results revealed that UC2288 (at concentrations of 10,20 and $50 \mathrm{nM}$ ) treatment with MPTP significantly increased the neuronal cell viability in a concentration-dependent manner (Fig. 5A). In order to investigate apoptosis of neuronal cells, we performed a TUNEL assay in the primary cultured neuronal cells. In the MPTP group, TUNELpositive apoptotic cells were significantly higher in the MPTP treated group, but the number of apoptotic cells was decreased by UC2288 treatment (Fig. 5B). As shown in Fig. 5C, whole-cell intracellular ROS production was also quantified as an index of MPTP-induced oxidative stress. Exposure for $24 \mathrm{~h}$ to $100 \mu \mathrm{M}$ MPTP caused increase $\mathrm{H}_{2} \mathrm{O}_{2}$ and decreased GSH levels, while treatment with UC2288 returned their levels to their previous values (Fig. 5C).

\section{UC2288 inhibited p21 expression and suppressed MAPK pathway in vitro}

We co-treated UC2288 and MPP + in primary cultured neurons. There was no significant difference with UC2288 (50 nM) treatment alone. However, treatment of MPP + increased p-p21 level, but UC2288 reduced its expression (Fig. 6A). Moreover, the expression of MAPK family; (p-ERK, p-JNK, p-P38, and iNOS and COX-2) was increased by MPP+, but their expression was decreased by UC2288 treatment in primary cultured neurons (Fig. 6B). Of the MAPK family, the MPP+-induced phosphorylation of ERK was most significantly decreased by UC2288 (Fig. 6B)

Inhibition of the ERK pathway abolished the recovering effect of p21 inhibitor on MPP + induced ROS and IL-6 and cell death in vitro

Exposure for $24 \mathrm{~h}$ to MPP+ $(100 \mu \mathrm{M})$ causes cell death in cultured neurons. However, inhibition of ERK kinase (U0126) increased cell viability. The inhibition of ERK most dramatically reduced cell death in 5 and $10 \mu \mathrm{M}(\mathrm{Fig} .7 \mathrm{~A})$. However, the abolishment of the ERK pathway by U0126 treatment further increased $\mathrm{H}_{2} \mathrm{O}_{2}$ levels, while decreasing cell survival, but no changed IL-6 level (Fig. 7B).

\section{Discussion}

$\mathrm{PD}$ is one of the most prevalent neurodegenerative disease, and is characterized by typical motor manifestations including resting tremor, rigidity, bradykinesia, and postural instability ${ }^{2}$. Loss of dopaminergic neurons in the substantia nigra and the depletion of dopamine in the striatum are associated with these motor manifestations ${ }^{35}$. However, the specific mechanisms underlying these actions are clear, making it difficult to study ways to cure the disease. Previously, we showed that p21, a substrate of parkin, was not degraded in Park KO mouse through the loss of the ubiquitination ability of parkin, and thus reduced neurogenesis as well as BDNF, SNAP25 expression level compared to WT ${ }^{1}$. Moreover, a study showed that MPP + treatment resulted in the induction of p21 WAF1/Cip1 expression, which caused cell death in dopaminergic neurons ${ }^{36}$. Since the inhibition of neurogenesis is critical for 
the development of neurodegenerative diseases, we speculated that the inhibition of p21 could attenuate neuronal damages, which could have therapeutically positive effect on Parkinson's disease. We used an MPTP (20 mg/kg)-induced mouse PD model ${ }^{37}$. Our present data showed that UC2288 treatment reduced PD behavioral disorder and dopamine depletion, indicating that p21 could be useful for the treatment of PD. However, the mechanisms behind its effects remain unclear.

MPTP primarily causes oxidative stress in neurons. Glutathione (GSH) loss was reported as an early deficits in both PD patients and animal models ${ }^{38}$. MPTP-induced lipid peroxidation clearly led to neuronal cell damage ${ }^{39}$. Therefore, MPTP treatment induced dopaminergic neuronal damages through changes in anti-oxidative enzymes and lipid peroxidation in the monkey PD model ${ }^{40}$. Superoxide dismutase (SOD) could also reflect the occurrence of oxidative stress in PD ${ }^{41}$. MPTP induced suppression of the activities of SOD and CAT, could contribute to neuronal death ${ }^{41}$. Conversely, the alleviation of the activities of SOD and CAT prevent MPTP-induced dopaminergic neuronal death in the striatum ${ }^{42}$. Moreover, significant decreases in the activities of SOD and GST were observed in the striatum of the subjects with PD than in the striata of patients in the control group. ${ }^{43}$. When iron levels increased following an increased in anti-oxidants levels, ROS levels were attenuated, showing the protective role of oxidative stress in a Lipopolysaccharide PD model ${ }^{44}$. Moreover, it is interesting to note that p21 increased intracellular levels of ROS both in normal fibroblasts and in p53-negative cancer cells 45. In addition, p21 also inhibited nigral activation of p2 $1^{\text {ras }}$ and p2 $1^{\text {rac }}$ as well as the level of GSH, and also significantly protected the MPTP-induced nigrostriatal neurons via the increase of GSH ${ }^{46}$. Our studies also showed that treatment of UC2288 recovered MPTP induced decreases of GSH. We also observed that UC2288 treatment reduced MDA and $\mathrm{H}_{2} \mathrm{O}_{2}$ levels but recovered GSH levels. Thus, these data suggest that the anti-oxidative effect of p21 inhibitor could contribute to the therapeutic effect on PD.

Neuroinflammation such as astrogliosis and microgliosis is one of the prominent characteristics of PD 47. Upon activation by brain injury and inflammatory stimuli, astrocytes and microglia excreted amounts of proinflammatory factors such as cytokines and reactive oxygen species (ROS). The accumulation of these factors was recognized as causing the progressive loss of dopaminergic neurons ${ }^{4849}$, Moreover, microglia and astrocytes were activated in PD models ${ }^{50}$. Thus, the inhibition of neuroinflammation exhibits promising therapeutic potential for PD. Therefore several anti-inflammatory agents have been suggested to inhibit the progression of the disorder ${ }^{51-53}$.

In the present study, p21 inhibitor reduced the expression of iNOS, TNF- $\alpha$ and IL-1 $\beta$ levels as well as activation of astrocytes and microglia in a mouse PD model ${ }^{46}$. In support of our data, it was reported that p21 knockout prevented angiotensin II-induced NF-KB activation through reduced ROS generation in vitro and in vivo ${ }^{54}$, and that LPS induced neuroinflammation ${ }^{55}$. Thus, the anti-neuroinflammatory effects of p21 inhibitor could be also associated with neuroprotective and anti-PD effects. 
Several studies have showned that MAPK phosphorylation was activated in a cell-specific manner in the MPTP mouse model ${ }^{56}$. In addition, the activation of p38 kinase and c-Jun N-terminal kinase (JNK) caused neuronal cell death ${ }^{57}$. Further, recent studies have demonstrated that p38 MAPK and JNK were activated by neurotoxicants, stress, or inflammation, and that these activations may be responsible for the development of PD. Thus, the blocking of the p38 MAPK and JNK pathways may aid the development of therapeutic effects for PD patients ${ }^{5859}$. A previous study also indicated that homocysteine-NMDA receptor induced activation of p38 and ERK induced neuronal cell death ${ }^{6061}$. Moreover, treatment of ERK kinase inhibitor reduced neuronal cell death against oxidative stress ${ }^{62}$. The inhibition of JNK attenuated neuronal cell death and inflammation-induced cerebral malaria ${ }^{63}$. In our study, p-ERK, p-JNK and p38 were activated by the administration of MPTP, but UC2288 treatment reduced their phosphorylation. Accompanying the prevention of MAPK was activation, and UC2288 treatment suppressed neuronal cell death in MPTP treated mice brains and cultured neuronal cells. BAX and cleavead-caspase 3 levels were also reduced by UC2288. In addition, treatment of p-ERK, p-JNK and p-p38 inhibitors would recover MPP+induced cell death with the most effectiveness by ERK kinase inhibitor. However, surprisingly, the abolishment of the ERK pathway further decreased cell survival with increased $\mathrm{H} 2 \mathrm{O} 2$. This may be due to the inhibition of the prevented ERK pathway. Taken together, these data indicated that the MAPK pathway (and perhaps ERK pathway) could be associated with the preventive effects of p21 inhibitor. Combined with the findings of previous studies ${ }^{1}$, our present data conclusively suggest that $p 21$ may be a target of PD, and that 211 inhibition could be beneficial for stalling the progression of PD.

\section{Conclusion}

In conclusion, our systematic study investigated the effect of UC2288, a inhibitor of P21, on the therapeutic effects of PD. The administration of UC2288 inhibited neuroinflammatory and oxidative stress by inhibiting ERK pathway. Neuroprotective effects on the death of dopaminergic neurons have been shown.

\section{Abbreviations}

PD

Parkinson's disease

MPTP

1-methyl-4-phenyl-1,2,3,6-tetrahydropyridine

AADC

aromatic amino acid decarboxylase

GAD

glutamic acid decarboxylase

GDNF

glial cell line-derived neurotrophic factor

ROS 
Reactive Oxygen Species

MAPK

mitogen activated protein kinase

6-OHDA

6-hydroxydopamine

PBS

phosphate-buffered saline

TBA

thiobarbituric acid

ECL

enhanced chemiluminescence

ELISA

enzyme-linked immunosorbent assay

DAB

diaminobenzidine tetrahydrochloride

DAPI

60-diamidino-2-phenylindole dihydrochloride

\section{Declarations}

\section{Ethics approval}

Administration for the human care and use of laboratory animals and approved by IACUC of Chung-buk National University CBNUR-1117-18.

\section{Consent for publication}

Not applicable.

\section{Availability of data and material}

All data generated and analyzed during the current study are included in this published article and its supplementary files.

\section{Competing interests}

Not applicable.

\section{Funding}

This work was supported by the National Research Foundation of Korea (NRF) grant funded by the Korea government (MSIP) (NO. MRC2017R1A5A2015541)

\section{Authors' Contributions}


JHI, IJY, SHJ, DHL, HJH, JSY, SBH, and JTH conceived, performed, and analyzed the experiments. JTH wrote and edited the manuscript. All authors read and approved the final manuscript.

\section{Acknowledgments}

The authors acknowledge the following persons for assistance with enrollment: Jun Hyung Im, In Jun Yeo, Seong Hee Jeon, Dong Hun Lee, Hyeon Joo Ham, Jaesuk Yun, Sang-Bae Han and Jin Tae Hong.

\section{References}

1. Park MH, Lee HJ, Lee HL, et al. Parkin Knockout Inhibits Neuronal Development via Regulation of Proteasomal Degradation of p21. Theranostics. 2017;7(7):2033-45.

2. Mhyre TR, Boyd JT, Hamill RW, Maguire-Zeiss KA. Parkinson's disease. Sub-cellular biochemistry. 2012;65:389-455.

3. Chen Y, Lian Y, Ma Y, Wu C, Zheng Y, Xie N. The expression and significance of tyrosine hydroxylase in the brain tissue of Parkinsons disease rats. Experimental therapeutic medicine. 2017;14(5):48136.

4. Cotzias GC, Papavasiliou PS, Gellene R. L-dopa in parkinson's syndrome. The New England journal of medicine. 1969;281(5):272.

5. Coune PG, Schneider BL, Aebischer P. Parkinson's disease: gene therapies. Cold Spring Harbor perspectives in medicine. 2012;2(4):a009431.

6. Muramatsu S, Fujimoto K, Kato S, et al. A phase I study of aromatic L-amino acid decarboxylase gene therapy for Parkinson's disease. Molecular therapy: the journal of the American Society of Gene Therapy. 2010;18(9):1731-5.

7. Emborg ME, Carbon M, Holden JE, et al. Subthalamic glutamic acid decarboxylase gene therapy: changes in motor function and cortical metabolism. Journal of cerebral blood flow metabolism: official journal of the International Society of Cerebral Blood Flow Metabolism. 2007;27(3):501-9.

8. Even Ram S, Galun E. AAV2-GDNF gene therapy for Parkinson's disease. Human gene therapy. 2009;20(5):430-1.

9. Filograna R, Beltramini M, Bubacco L, Bisaglia M. Anti-Oxidants in Parkinson's Disease Therapy: A Critical Point of View. Current neuropharmacology. 2016;14(3):260-71.

10. Gong L, Daigneault EA, Acuff RV, Kostrzewa RM. Vitamin E supplements fail to protect mice from acute MPTP neurotoxicity. Neuroreport. 1991;2(9):544-6.

11. Beal MF, Matthews RT, Tieleman A, Shults CW. Coenzyme Q10 attenuates the 1-methyl-4-phenyl$1,2,3$,tetrahydropyridine (MPTP) induced loss of striatal dopamine and dopaminergic axons in aged mice. Brain research. 1998;783(1):109-14.

12. Horvath $T L$, Diano $S$, Leranth $C$, et al. Coenzyme $Q$ induces nigral mitochondrial uncoupling and prevents dopamine cell loss in a primate model of Parkinson's disease. Endocrinology. 2003;144(7):2757-60. 
13. Silva RM, Kuan CY, Rakic P, Burke RE. Mixed lineage kinase-c-jun N-terminal kinase signaling pathway: a new therapeutic target in Parkinson's disease. Movement disorders: official journal of the Movement Disorder Society. 2005;20(6):653-64.

14. Kulisz A, Chen N, Chandel NS, Shao Z, Schumacker PT. Mitochondrial ROS initiate phosphorylation of p38 MAP kinase during hypoxia in cardiomyocytes. American journal of physiology Lung cellular molecular physiology. 2002;282(6):L1324-9.

15. McCubrey JA, Lahair MM, Franklin RA. Reactive oxygen species-induced activation of the MAP kinase signaling pathways. Antioxidants redox signaling. 2006;8(9-10):1775-89.

16. Klegeris A, Pelech S, Giasson Bl, et al. Alpha-synuclein activates stress signaling protein kinases in THP-1 cells and microglia. Neurobiology of aging. 2008;29(5):739-52.

17. Newhouse K, Hsuan SL, Chang SH, Cai B, Wang Y, Xia Z. Rotenone-induced apoptosis is mediated by p38 and JNK MAP kinases in human dopaminergic SH-SY5Y cells. Toxicological sciences: an official journal of the Society of Toxicology. 2004;79(1):137-46.

18. Rawal N, Parish C, Castelo-Branco G, Arenas E. Inhibition of JNK increases survival of transplanted dopamine neurons in Parkinsonian rats. Cell death differentiation. 2007;14(2):381-3.

19. Hunot S, Vila M, Teismann P, et al. JNK-mediated induction of cyclooxygenase 2 is required for neurodegeneration in a mouse model of Parkinson's disease. Proceedings of the National Academy of Sciences of the United States of America. 2004;101(2):665-70.

20. Kulich SM, Chu CT. Sustained extracellular signal-regulated kinase activation by 6-hydroxydopamine: implications for Parkinson's disease. Journal of neurochemistry. 2001;77(4):1058-66.

21. McCarthy S, Somayajulu M, Sikorska M, Borowy-Borowski H, Pandey S. Paraquat induces oxidative stress and neuronal cell death; neuroprotection by water-soluble Coenzyme Q10. Toxicology applied pharmacology. 2004;201(1):21-31.

22. Xu C, Wang X, Zhu Y, et al. Rapamycin ameliorates cadmium-induced activation of MAPK pathway and neuronal apoptosis by preventing mitochondrial ROS inactivation of PP2A. Neuropharmacology. 2016;105:270-84.

23. Dawson TM, Dawson VL. The role of parkin in familial and sporadic Parkinson's disease. Movement disorders: official journal of the Movement Disorder Society. 2010;25(Suppl 1):32-9.

24. Rial D, Castro AA, Machado N, et al. Behavioral phenotyping of Parkin-deficient mice: looking for early preclinical features of Parkinson's disease. PloS one. 2014;9(12):e114216.

25. Petrucelli L, O'Farrell C, Lockhart PJ, et al. Parkin protects against the toxicity associated with mutant alpha-synuclein: proteasome dysfunction selectively affects catecholaminergic neurons. Neuron. 2002;36(6):1007-19.

26. Yamada M, Mizuno Y, Mochizuki H. Parkin gene therapy for alpha-synucleinopathy: a rat model of Parkinson's disease. Human gene therapy. 2005;16(2):262-70.

27. Ghosh A, Roy A, Matras J, Brahmachari S, Gendelman HE, Pahan K. Simvastatin inhibits the activation of p21ras and prevents the loss of dopaminergic neurons in a mouse model of Parkinson's 
disease. The Journal of neuroscience: the official journal of the Society for Neuroscience. 2009;29(43):13543-56.

28. Esteras N, Alquezar C, Bartolome F, et al. G1/S Cell Cycle Checkpoint Dysfunction in Lymphoblasts from Sporadic Parkinson's Disease Patients. Molecular neurobiology. 2015;52(1):386-98.

29. Bialopiotrowicz E, Szybinska A, Kuzniewska B, et al. Highly pathogenic Alzheimer's disease presenilin 1 P117R mutation causes a specific increase in p53 and p21 protein levels and cell cycle dysregulation in human lymphocytes. Journal of Alzheimer's disease: JAD. 2012;32(2):397-415.

30. Romani-Aumedes J, Canal M, Martin-Flores N, et al. Parkin loss of function contributes to RTP801 elevation and neurodegeneration in Parkinson's disease. Cell death disease. 2014;5:e1364.

31. Vercammen L, Van der Perren A, Vaudano E, et al. Parkin protects against neurotoxicity in the 6hydroxydopamine rat model for Parkinson's disease. Molecular therapy: the journal of the American Society of Gene Therapy. 2006;14(5):716-23.

32. Hwang CJ, Kim YE, Son DJ, et al. Parkin deficiency exacerbate ethanol-induced dopaminergic neurodegeneration by P38 pathway dependent inhibition of autophagy and mitochondrial function. Redox biology. 2017;11:456-68.

33. Choi DY, Lee MK, Hong JT. Lack of CCR5 modifies glial phenotypes and population of the nigral dopaminergic neurons, but not MPTP-induced dopaminergic neurodegeneration. Neurobiology of disease. 2013;49:159-68.

34. Li Z, Wu Y, Chen HP, et al. MTOR Suppresses Environmental Particle-Induced Inflammatory Response in Macrophages. Journal of immunology. 2018;200(8):2826-34.

35. Tolosa E, Marti MJ, Valldeoriola F, Molinuevo JL. History of levodopa and dopamine agonists in Parkinson's disease treatment. Neurology. 1998;50(6 Suppl 6):2-10. discussion S44-18.

36. Soldner F, Weller M, Haid S, et al. MPP + inhibits proliferation of PC12 cells by a p21(WAF1/Cip1)dependent pathway and induces cell death in cells lacking p21(WAF1/Cip1). Experimental cell research. 1999;250(1):75-85.

37. Yazihan N, Uzuner K, Salman B, Vural M, Koken T, Arslantas A. Erythropoietin improves oxidative stress following spinal cord trauma in rats. Injury. 2008;39(12):1408-13.

38. Dauer W, Przedborski S. Parkinson's disease: mechanisms and models. Neuron. 2003;39(6):889909.

39. Ren YH, Niu XY, Huang HJ, et al. Dopamine neuron loss by selective deletion of autophagy-related gene 5 is not exacerbated by MPTP toxicity in midbrain. Neuroscience letters. 2017;675:140-4.

40. Li L, Shi L, Liu H, et al. Changes in blood anti-oxidation enzyme levels in MPTP-treated monkeys. Neuroscience letters. 2017;649:93-9.

41. Jenner P, Olanow CW. Oxidative stress and the pathogenesis of Parkinson's disease. Neurology. 1996;47(6 Suppl 3):161-70.

42. Weydert CJ, Cullen JJ. Measurement of superoxide dismutase, catalase and glutathione peroxidase in cultured cells and tissue. Nature protocols. 2010;5(1):51-66. 
43. Riederer P, Sofic E, Rausch WD, et al. Transition metals, ferritin, glutathione, and ascorbic acid in parkinsonian brains. Journal of neurochemistry. 1989;52(2):515-20.

44. Sharma N, Nehru B. Curcumin affords neuroprotection and inhibits alpha-synuclein aggregation in lipopolysaccharide-induced Parkinson's disease model. Inflammopharmacology. 2018;26(2):349-60.

45. Macip S, Igarashi M, Fang L, et al. Inhibition of p21-mediated ROS accumulation can rescue p21induced senescence. The EMBO journal. 2002;21(9):2180-8.

46. Roy A, Ghosh A, Jana A, et al. Sodium phenylbutyrate controls neuroinflammatory and antioxidant activities and protects dopaminergic neurons in mouse models of Parkinson's disease. PloS one. 2012;7(6):e38113.

47. Costa SL, Silva VD, Dos Santos Souza C, et al. Impact of Plant-Derived Flavonoids on Neurodegenerative Diseases. Neurotoxicity research. 2016;30(1):41-52.

48. Block ML, Zecca L, Hong JS. Microglia-mediated neurotoxicity: uncovering the molecular mechanisms. Nature reviews Neuroscience. 2007;8(1):57-69.

49. Pott Godoy MC, Tarelli R, Ferrari CC, Sarchi MI, Pitossi FJ. Central and systemic IL-1 exacerbates neurodegeneration and motor symptoms in a model of Parkinson's disease. Brain: a journal of neurology. 2008;131(Pt 7):1880-94.

50. Costa G, Simola N, Morelli M. MDMA administration during adolescence exacerbates MPTP-induced cognitive impairment and neuroinflammation in the hippocampus and prefrontal cortex.

Psychopharmacology. 2014;231(20):4007-18.

51. Gagne JJ, Power MC. Anti-inflammatory drugs and risk of Parkinson disease: a meta-analysis. Neurology. 2010;74(12):995-1002.

52. Ton TG, Heckbert SR, Longstreth WT Jr, et al. Nonsteroidal anti-inflammatory drugs and risk of Parkinson's disease. Movement disorders: official journal of the Movement Disorder Society. 2006;21(7):964-9.

53. Whitton PS. Neuroinflammation and the prospects for anti-inflammatory treatment of Parkinson's disease. Current opinion in investigational drugs. 2010;11(7):788-94.

54. Kunieda T, Minamino T, Nishi J, et al. Angiotensin II induces premature senescence of vascular smooth muscle cells and accelerates the development of atherosclerosis via a p21-dependent pathway. Circulation. 2006;114(9):953-60.

55. Tusell JM, Saura J, Serratosa J. Absence of the cell cycle inhibitor p21Cip1 reduces LPS-induced NO release and activation of the transcription factor NF-kappaB in mixed glial cultures. Glia. 2005;49(1):52-8.

56. Karunakaran S, Diwakar L, Saeed U, et al. Activation of apoptosis signal regulating kinase 1 (ASK1) and translocation of death-associated protein, Daxx, in substantia nigra pars compacta in a mouse model of Parkinson's disease: protection by alpha-lipoic acid. FASEB journal: official publication of the Federation of American Societies for Experimental Biology. 2007;21(9):2226-36.

57. Ray A, Sehgal N, Karunakaran S, Rangarajan G, Ravindranath V. MPTP activates ASK1-p38 MAPK signaling pathway through TNF-dependent Trx1 oxidation in parkinsonism mouse model. Free 
radical biology medicine. 2015;87:312-25.

58. Peng J, Andersen JK. The role of c-Jun N-terminal kinase (JNK) in Parkinson's disease. IUBMB life. 2003;55(4-5):267-71.

59. Karunakaran S, Ravindranath V. Activation of p38 MAPK in the substantia nigra leads to nuclear translocation of NF-kappaB in MPTP-treated mice: implication in Parkinson's disease. Journal of neurochemistry. 2009;109(6):1791-9.

60. Poddar R, Paul S. Novel crosstalk between ERK MAPK and p38 MAPK leads to homocysteine-NMDA receptor-mediated neuronal cell death. Journal of neurochemistry. 2013;124(4):558-70.

61. Liu XW, Ji EF, He P, Xing RX, Tian BX, Li XD. Protective effects of the p38 MAPK inhibitor SB203580 on NMDAinduced injury in primary cerebral cortical neurons. Molecular medicine reports. 2014;10(4):1942-8.

62. Satoh T, Nakatsuka D, Watanabe Y, Nagata I, Kikuchi H, Namura S. Neuroprotection by MAPK/ERK kinase inhibition with U0126 against oxidative stress in a mouse neuronal cell line and rat primary cultured cortical neurons. Neuroscience letters. 2000;288(2):163-6.

63. Anand SS, Maruthi M, Babu PP. The specific, reversible JNK inhibitor SP600125 improves survivability and attenuates neuronal cell death in experimental cerebral malaria (ECM). Parasitology research. 2013;112(5):1959-66.

\section{Figures}



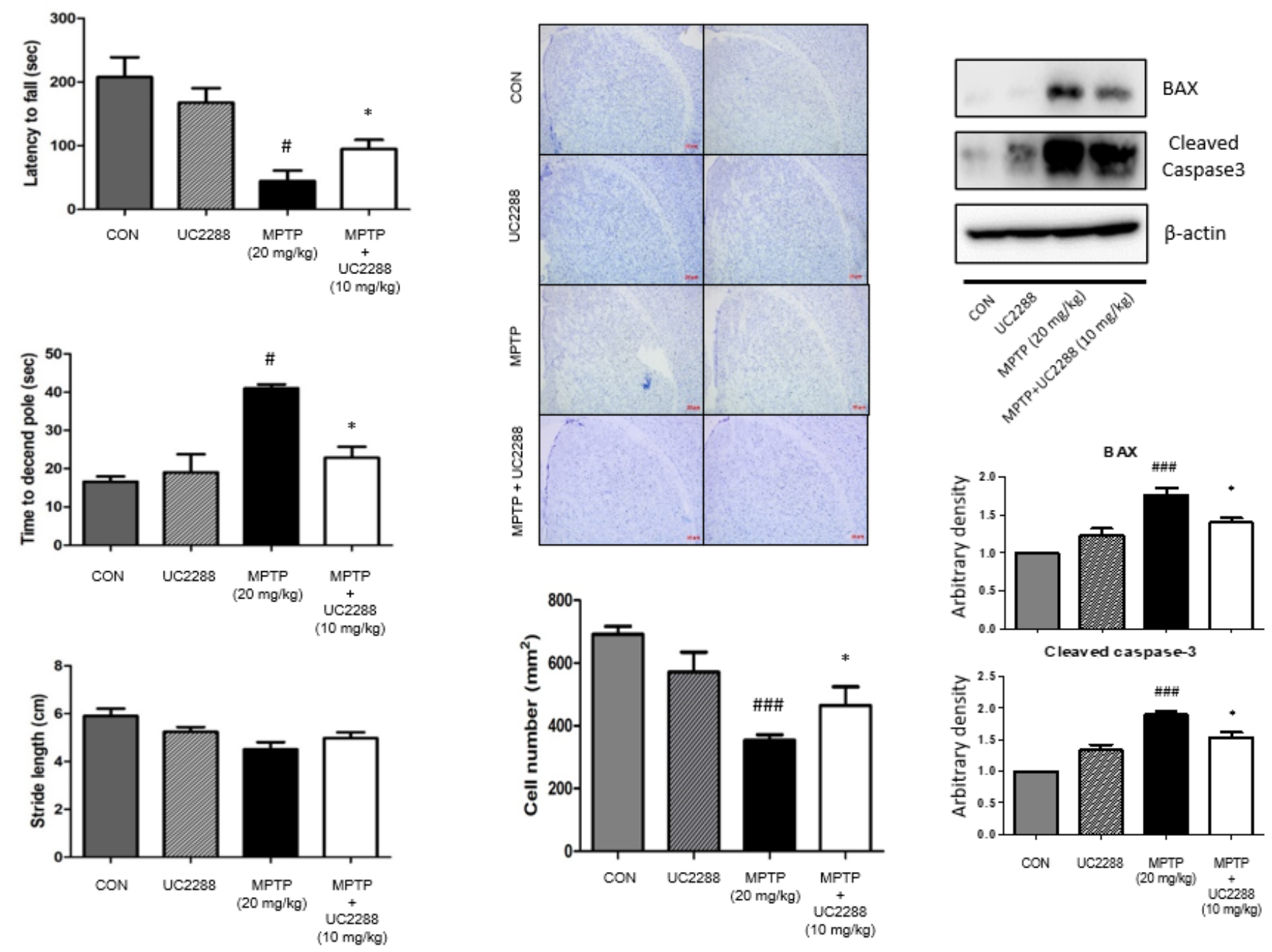

\section{Figure 2}

Effect of UC2288 on behavior impairments and suppressed apoptosis by MPTP. (A) Test was performed by an investigator blinded to the experimental groups. In order to perform the rota-rod test, the mice were trained on learning day. After one day, the retention time on the test stick was recorded. MPTP-induced bradykinesia (in the performance of the pole test when animals descended the length of the pole) was reduced in UC2288 treated mice. the stride length of the forelimb is attenuated by UC288 treatment, but this trend was not statistically significant. (B) The brain sections were washed twice with PBS and fixed by incubation in $4 \%$ paraformaldehyde for $1 \mathrm{~h}$ at room temperature. Neuronal cells were stained with cresyl violet. The graph represents quantitation of the number of neuronal cells/area. (C) The activations of caspase $3, \mathrm{Bcl}-2$, and BAX were measured using antibodies against BAX and total CCP3. Equal loading of samples was confirmed by monitoring $\beta$-actin. Each value is presented as mean $\pm S D$ from eight mice. $\#, P<0.05$ : significant difference from Control mice and *, $P<0.05$ : significant difference from MPTP and MPTP + UC2288 mice. 
A
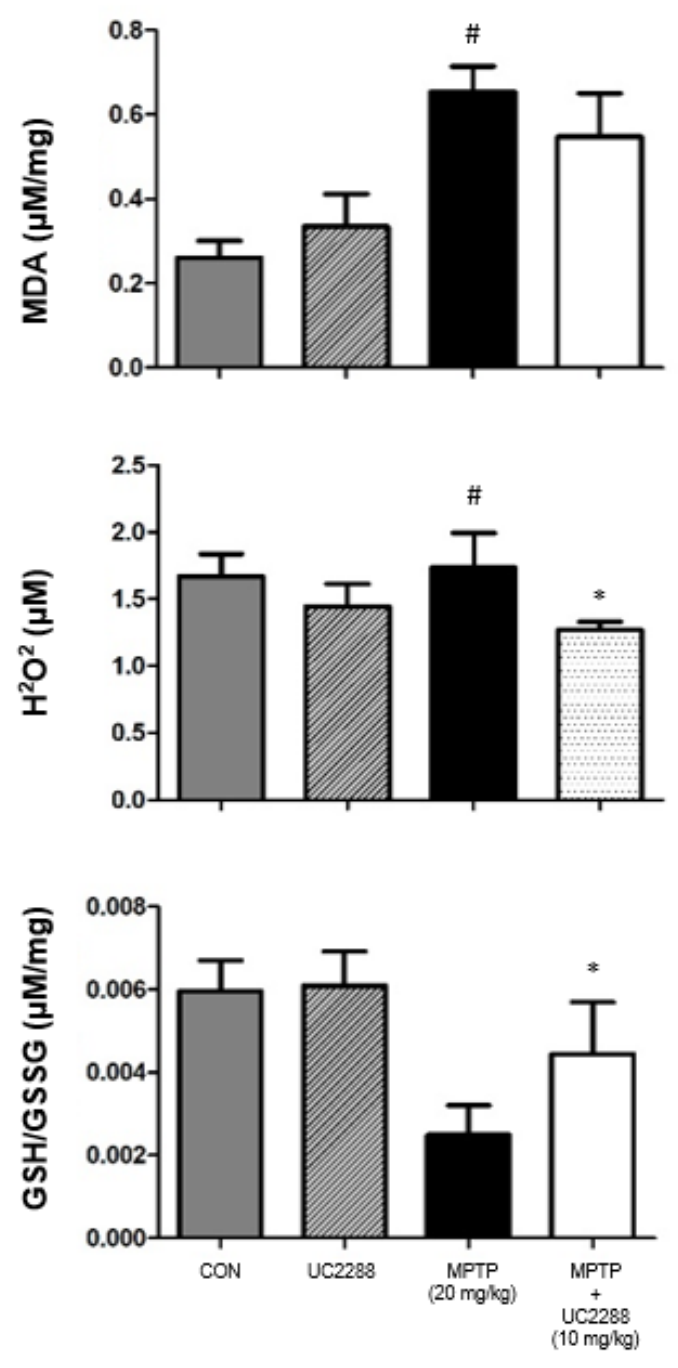

B
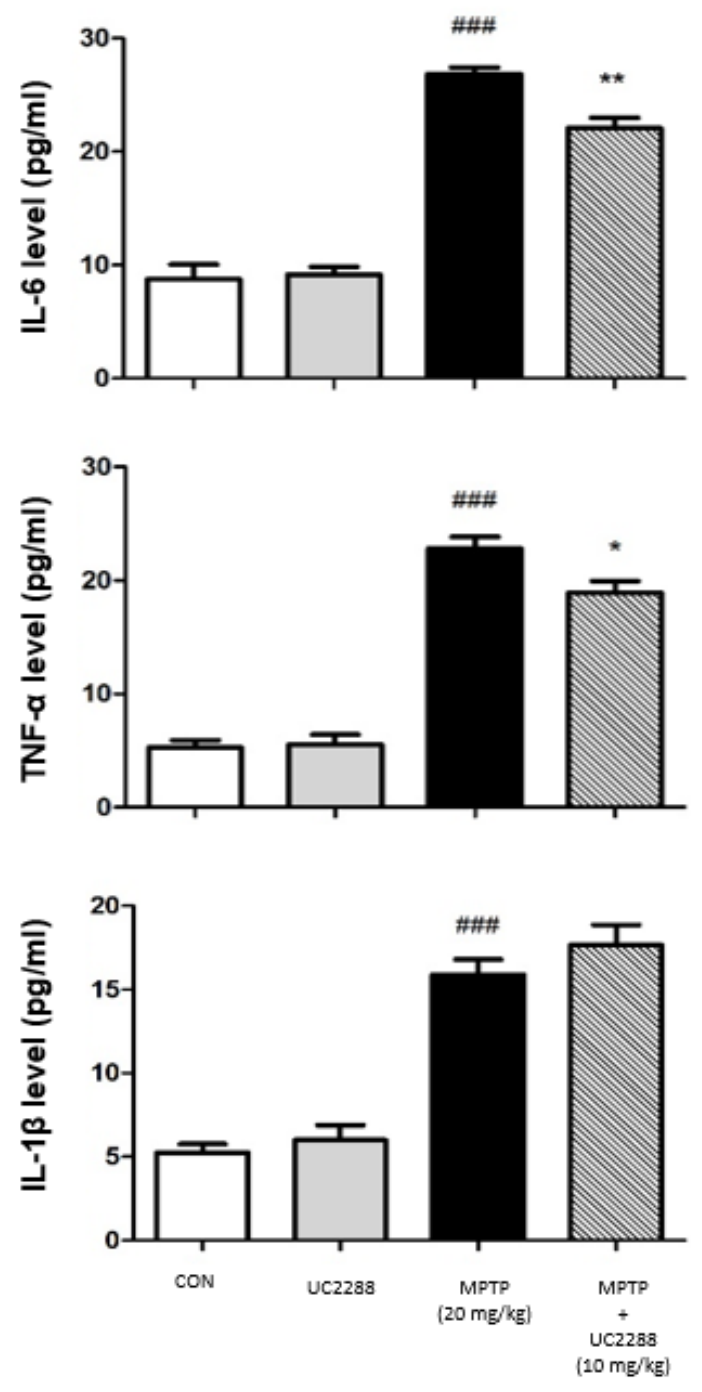

\section{Figure 4}

Effect of UC2288 on ROS generation, lipid peroxidation and inflammatory cytokines level. (A) MDA levels in the brain striatum site were measured using a TBARS assay kit. $\mathrm{H} 2 \mathrm{O} 2$ levels in the brain striatum site were measured using an $\mathrm{H} 2 \mathrm{O} 2$ assay kit. GSH/GSSG levels in the brain striatum site were measured using a GSH/GSSG Ratio Detection Assay Kit. (B) Serum levels of cytokines were measured by ELISA. Inflammatory cytokines (TNF-a, IL-6, and IL-1 $\beta$ ) were also examined. Each value is presented as mean $\pm S D$ from eight mice. \#, $P<0.05$ : significant difference from Control mice and *, $P<0.05$ : significant difference from MPTP and MPTP + UC2288 mice. 
A
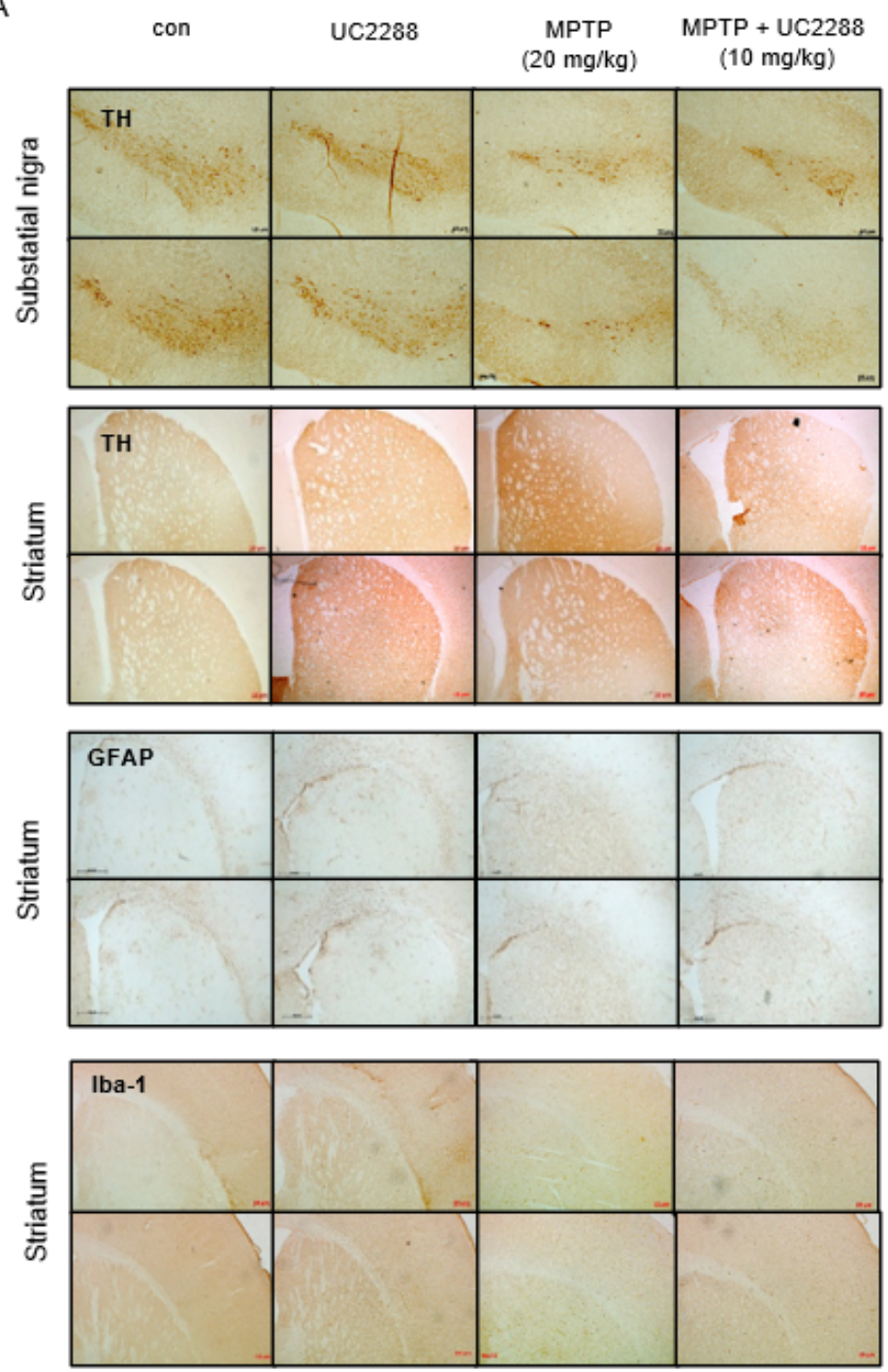

B
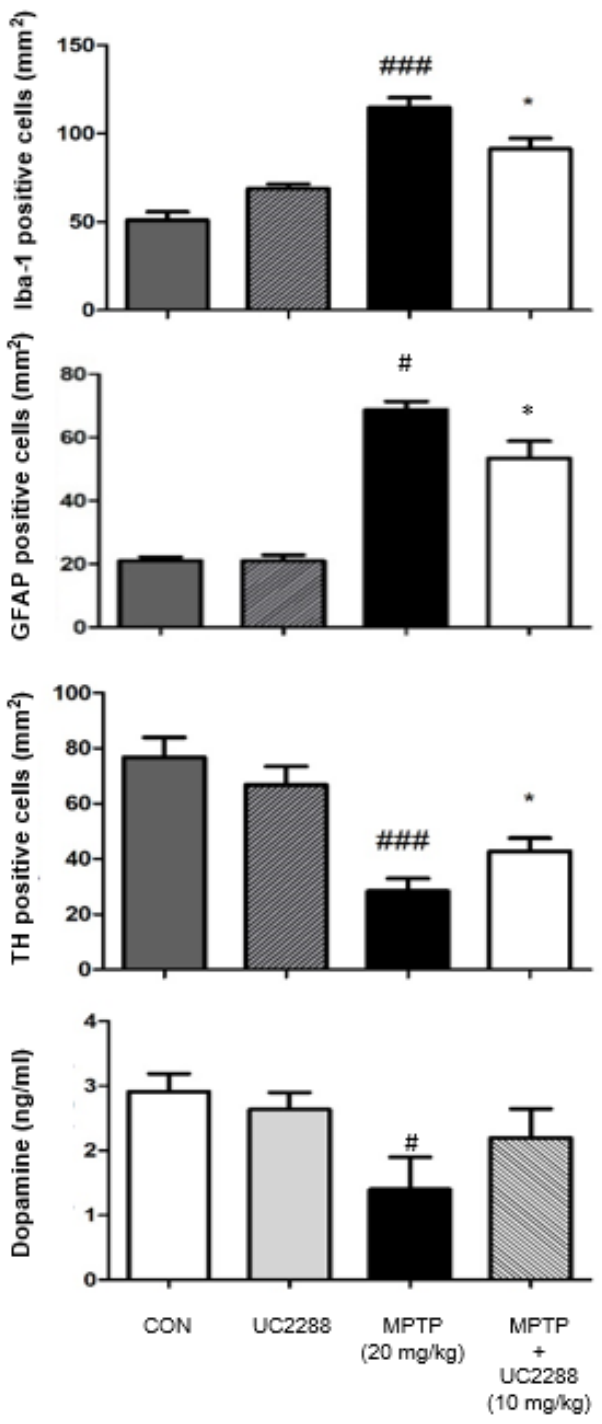

Figure 6

Effect of UC2288 on dopaminergic neurodegeneration. (A) The effect of UC2288 on TH-positive neurons was measured through immunohistochemical analysis. The two sections represent mice brains (striatum and substantia nigra) incubated with the anti-TH+ primary antibody and the biotinylated secondary antibody $(n=5)$. The representative stained tissues were viewed through a microscope. MPTP-induced loss of TH-positive fibers in the striatum, but UC2288 suppressed it. GFAP-positive astrocytes and Iba-1positive microglia/macrophages were found in the striatum $(n=5)$. (B) The graph represents the density of tissue sections and the number of TH, GFAP, and Iba-1 positive neuronal cells. In addition, the levels of dopamine in the striatum were measured by ELISA. All values are presented as mean $\pm S D$ from five mice. $\#, P<0.05$ : significant difference from Control mice and *, $\mathrm{P}<0.05$ : significant difference from MPTP and MPTP + UC2288 mice. 
A
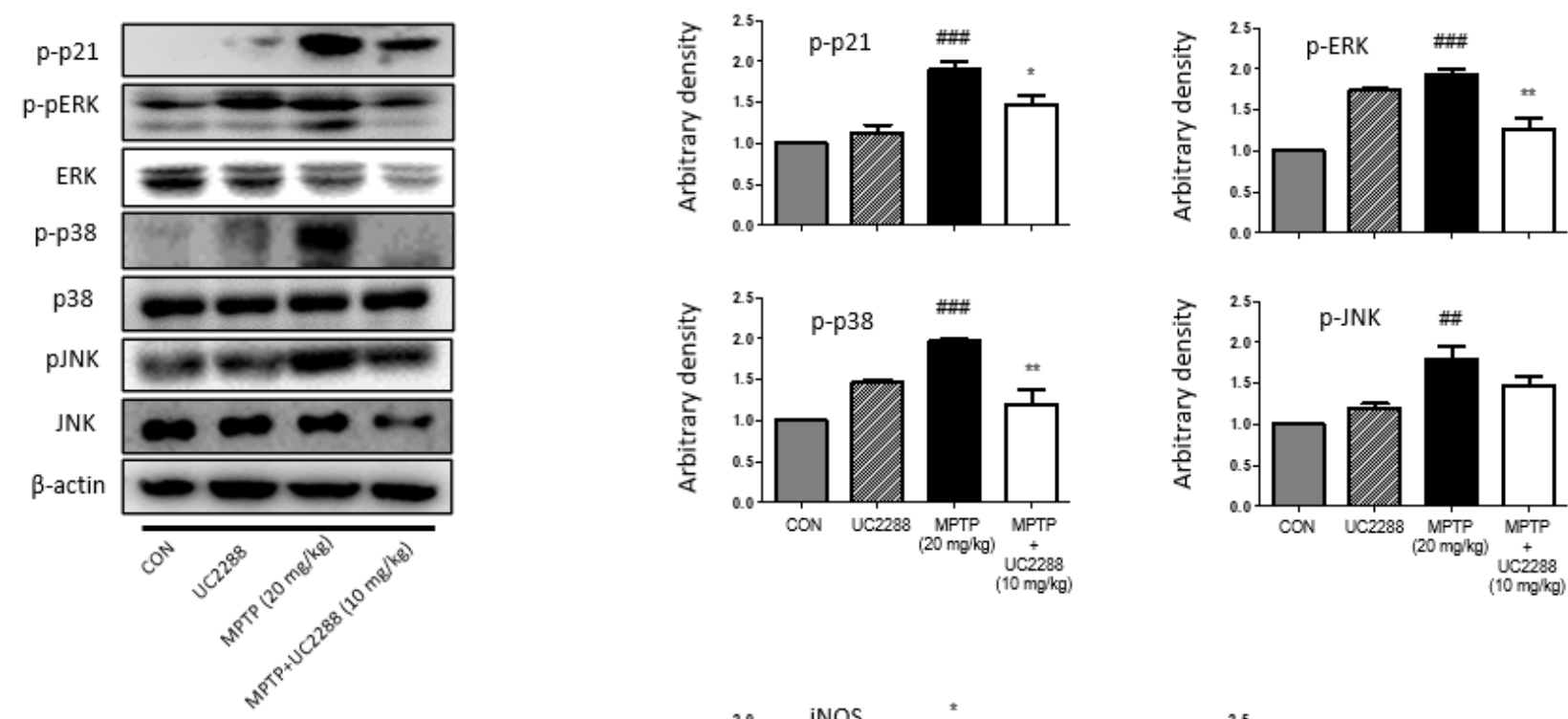

B
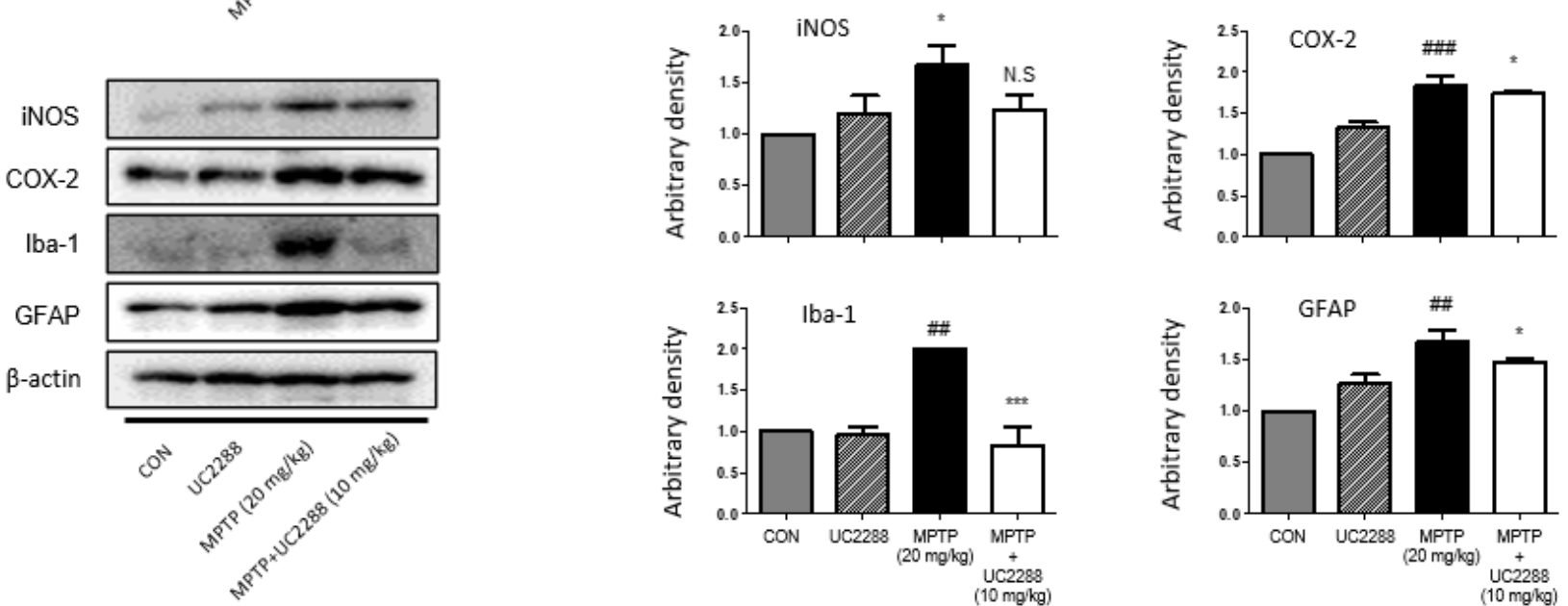

Figure 8

Involvement of MAPK pathway in the reduced ROS generation in mice brains. (A) Expressions of p21, EKR, p38, and JNK as well as their phosphorylated forms were measured through Western blotting. Equal loading was confirmed by monitoring the $\beta$-actin protein level. The expression levels were quantified by stereological analysis using the ImageJ program. (B) The expressions of iNOS, COX-2, Iba-1, and GFAP form were measured through Western blotting. Equal loading was confirmed by monitoring the $\beta$-actin protein level. The expression levels were quantified by stereological analysis using the ImageJ program. All values are presented as mean \pm SD from five mice. \#, $\mathrm{P}<0.05$ : significant difference from Control mice and *, P<0.05: significant difference from MPTP and MPTP + UC2288 mice. 


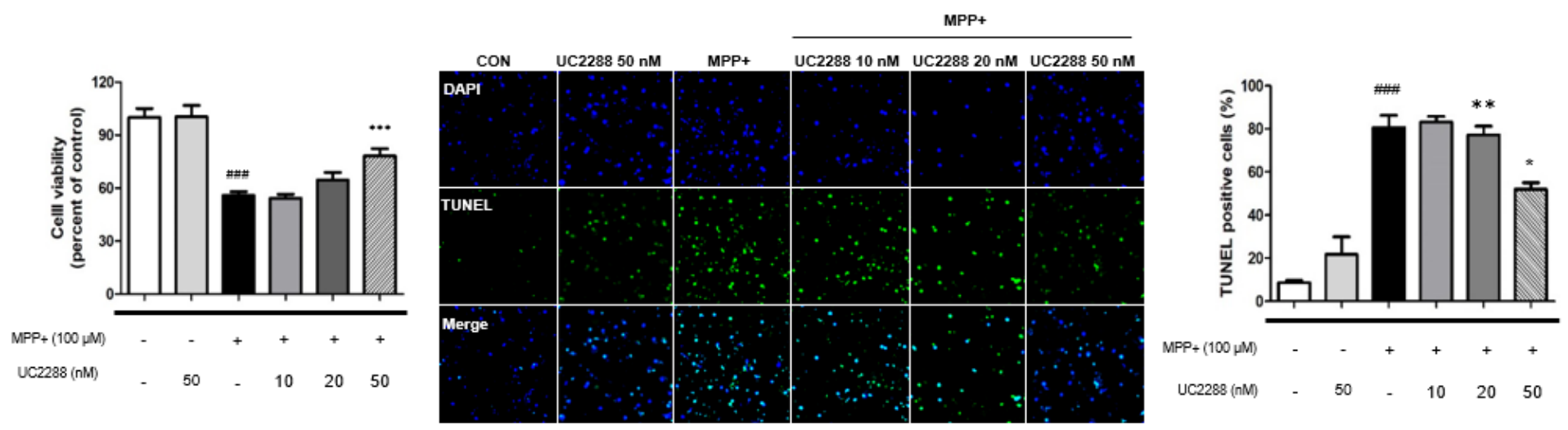

C

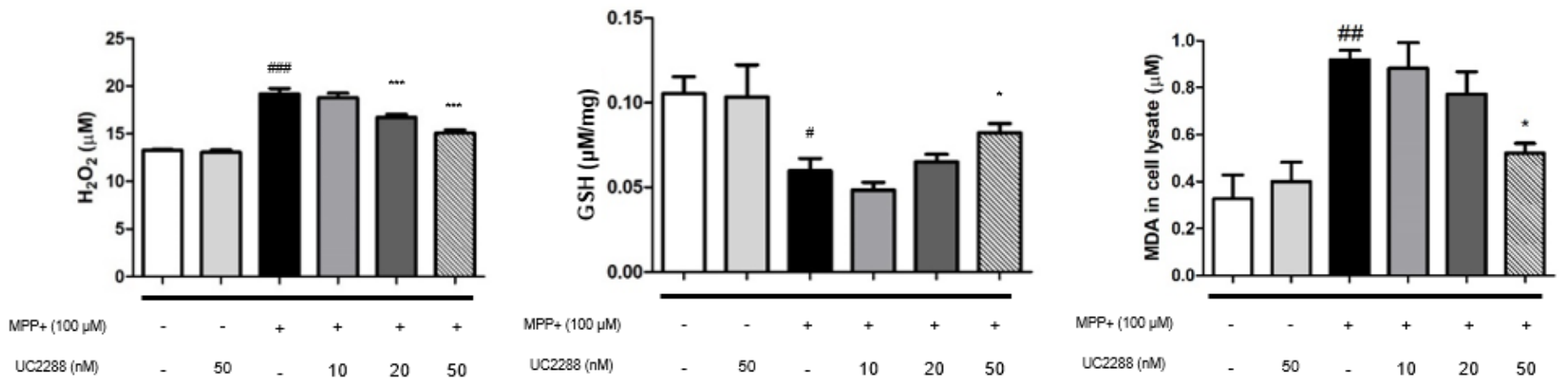

Figure 10

UC2288 suppressed cell death and ROS generation in vitro. Neuronal cells were pretreated for $2 \mathrm{~h}$ with UC2288 10, 20, or $50 \mathrm{nM}$ and then incubated with vehicle (Control) or the indicated MPP+ at a dose of $100 \mu \mathrm{M}$ for $24 \mathrm{~h}$. (A) Cell viability was examined by the MTT assay. (B) Apoptotic cell death was detected in six groups, as shown by TUNEL staining, described in the materials and methods. The representative stained cells were viewed through a microscope (X40). (C) H2O2 levels in the culture medium were measured using a hyperoxidation assay kit. GSH and MDA levels in the cell lysates were measured using a GSH and TBARS assay kit. The data are the mean \pm SD from three independent experiments $\#, p<0.05$ : compared with the control group and *, $p<0.05$ : compared with the MPP+ group. 

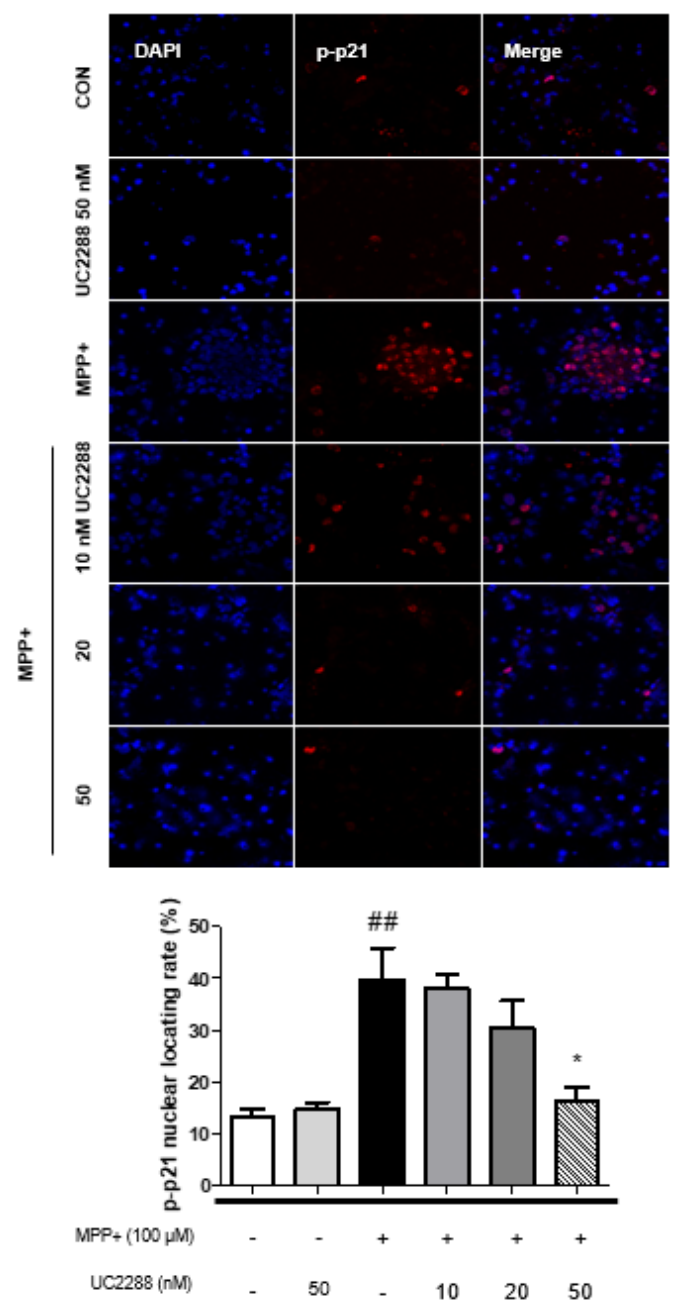
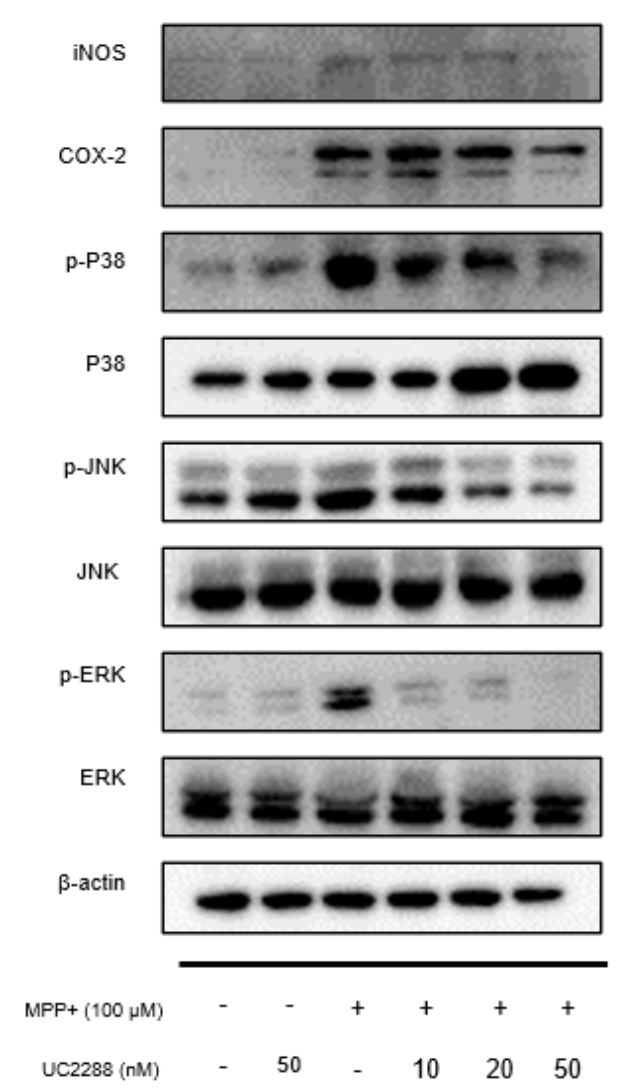

\section{Figure 12}

UC2288 suppressed p-p21 translocation to nuclear and MAPK activation. Neuronal cells were pretreated for $2 \mathrm{~h}$ with UC2288 10, 20, or $50 \mathrm{nM}$ then incubated with vehicle (Control) or the indicated MPP+ at a dose of $100 \mu \mathrm{M}$ for $24 \mathrm{~h}$. (A) Inhibition of p21 by UC2288 and, immunofluorescence staining of p-p21 was performed. Neuronal cells were incubated with specific antibodies against p-p21 (red) proteins. The representative stained cells were viewed through a microscope $(X 40)$. The ratio of $p-p 21$ located nuclear was measured for the quantification of fluorescence. (B) The expression of iNOS, COX-2, p-38, JNK, and ERK as well as their phosphorylated forms were measured through Western blotting. Equal loading was confirmed by monitoring the $\beta$-actin protein level. The expression levels were quantified by stereological analysis using the ImageJ program. The data are the mean \pm SD from three independent experiments \#, $p$ $<0.05$ : compared with the control group and *, $\mathrm{p}<0.05$ : compared with the MPP+ group. 
A
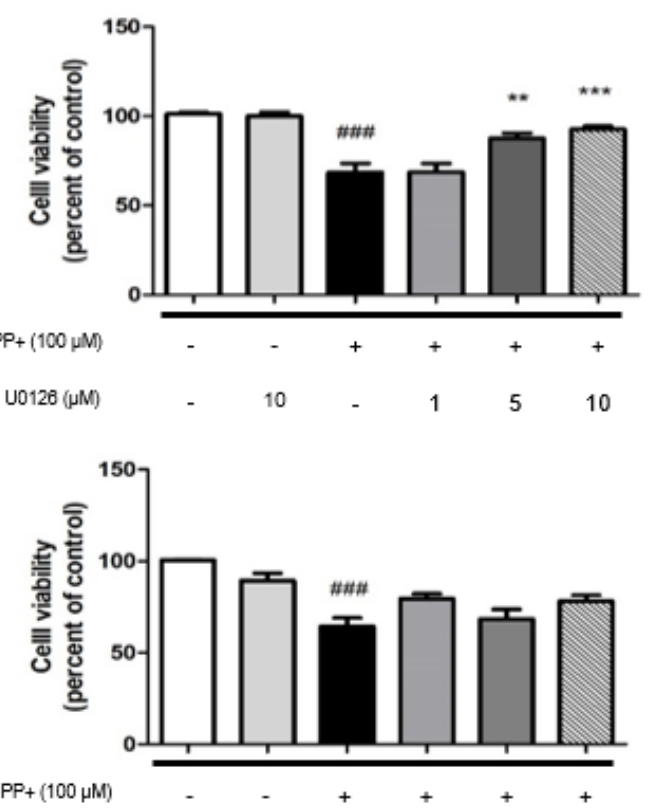

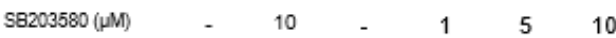

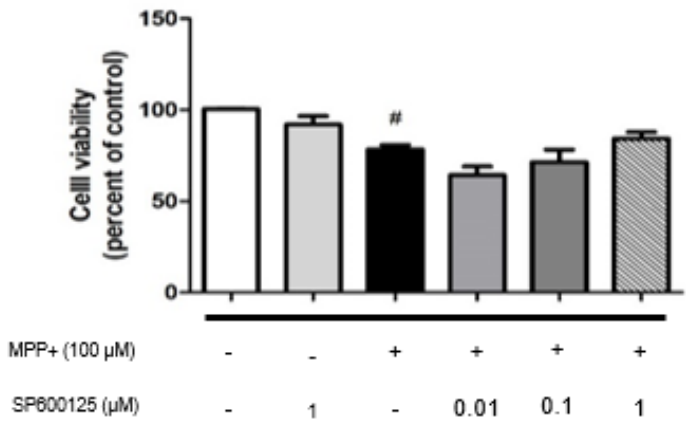

B
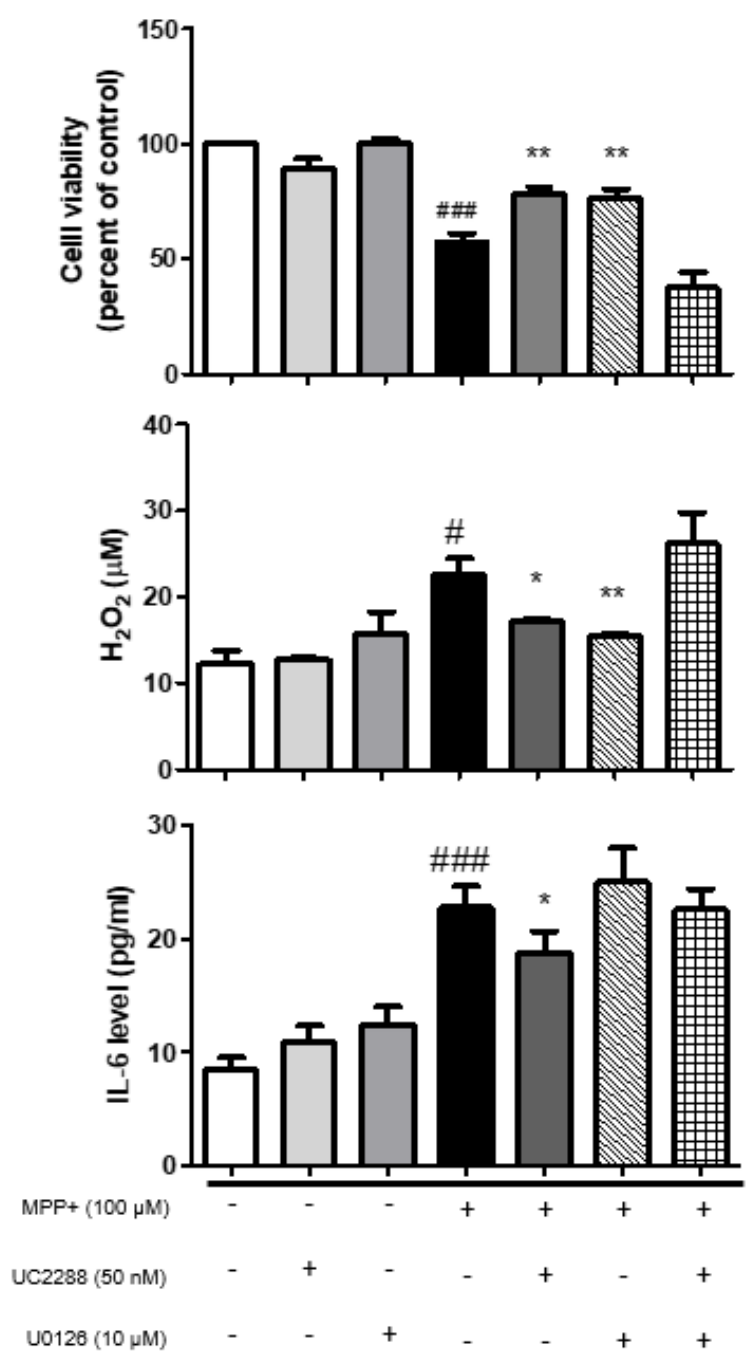

Figure 13

Inhibition of MAPK suppressed cell death and U0126 treatment reduced ROS damages by MPP+.

Neuronal cells were pretreated for 2 h with U0126, SB203580, or SP600125, then incubated with vehicle (Control) or the indicated MPP+ at a dose of $100 \mu \mathrm{M}$ for $24 \mathrm{~h}$. (A) Cell viability was examined by the MTT assay. (B) Neuronal cells were pretreated for $2 \mathrm{~h}$ with U0126 or UC2288 and then incubated with vehicle (Control) or the indicated MPP+ at a dose of $100 \mu \mathrm{M}$ for $24 \mathrm{~h} . \mathrm{H} 2 \mathrm{O} 2$ levels in the culture medium were measured using a hyperoxidation assay kit. IL- 6 levels of cytokines measured by ELISA. The data are the mean $\pm S D$ from three independent experiments \#, $p<0.05$ : compared with the control group and $*, p<$ 0.05: compared with the MPP+ group. 